This is a self-archived version of an original article. This version may differ from the original in pagination and typographic details.

Author(s): Sampson, James P.; Kettunen, Jaana; Vuorinen, Raimo

Title: The role of practitioners in helping persons make effective use of information and communication technology in career interventions

Year: 2020

Version: Accepted version (Final draft)

Copyright: ㄷ Springer Nature B.V. 2019

Rights: In Copyright

Rights url: http://rightsstatements.org/page/InC/1.0/?language=en

Please cite the original version:

Sampson, J. P., Kettunen, J., \& Vuorinen, R. (2020). The role of practitioners in helping persons make effective use of information and communication technology in career interventions. International Journal for Educational and Vocational Guidance, 20(1), 191-208.

https://doi.org/10.1007/s10775-019-09399-y 


\title{
The Role of Practitioners in Helping Persons Make Effective Use of Information and Communication Technology in Career Interventions
}

\author{
In Press (2019). International Journal for Educational and Career Guidance
}

James P. Sampson, Jr.

Center for the Study of Technology in Counseling and Career Development

Florida State University, 100 South Woodward Avenue, Tallahassee, Florida 32306-4162

\author{
Jaana Kettunen \\ Raimo Vuorinen \\ Finnish Institute for Educational Research \\ University of Jyväskylä, P.O. Box 35, 40014 Jyväskylä, Finland
}

Corresponding Author: James P. Sampson, Jr., jsampson@fsu.edu, 1850 322-8918

Acknowledgments: This article is based in part on a keynote address presented by the authors at the 2018 International Association for Educational and Vocational Guidance Conference, Gothenburg, Sweden. Helpful reviews of the manuscript were provided by Janet Lenz, Julia Makela, Debra Osborn, Matthew Sampson, and Sandy Sampson.

Keywords: practitioner role, information and communication technology, theory, research, training, policy

\begin{abstract}
We examine the role of counselors and other practitioners in delivering career interventions using Information and Communication Technology (ICT). Current benefits and limitations of ICT use provide the basis for recommendations. Potential benefits of increased ICT engagement include cost-effectiveness and improved access to resources and support. Potential limitations include poor assessment and information quality, limited practitioner support when needed, problems with distance intervention and social media, confidentiality of client records, inequality of access, inadequate competencies, and poor implementation. Specific practitioner roles are identified, and those related to social media are elaborated. Implications for theory, research, training, and policy are provided.
\end{abstract}

Career interventions are designed to assist clients and individuals manage their careers over the lifespan. These interventions range from providing intensive practitioner support over time for clients with extensive needs to providing self-help resources for individuals where practitioner support is not needed (Sampson \& Osborn, 2015). The career practitioners who design and deliver these interventions have titles that reflect their training, experience, credentials, and work setting, and include counselors, guidance specialists, psychologists, vocational rehabilitation specialists, teachers/faculty/academic advisers, librarians, human resource specialists, and social workers. Based on how and where they access career interventions, persons receiving assistance include clients, students/advisees, customers, patrons, and employees (Sampson, 2008). In this paper, the term "practitioner" is used for all professionals and paraprofessionals delivering career interventions, while persons receiving an intervention with practitioner support are referred to as "clients" and persons receiving a self-help intervention are referred to as "individuals."

Over the past 50 years information and communication technology (ICT) has become a common element of career interventions. ICT combines the data processing of computers with the data transmission of digital networks to increase access to career resources, as well as increase access to support from practitioners and other persons managing their careers (Hooley, Hutchinson, \& Watts, 2010; Kettunen \& Sampson, 2018; Sampson \& Osborn, 2015). Use of ICT in career interventions began with the automation of existing assessment and information resources. Personal computers, the Internet, tablets, and smartphones have substantially improved access to assessments and information, reduced the costs of development, and made practitioner intervention at a distance feasible. The more recent widespread use of social media by practitioners, clients, and individuals has further increased access to information and support from peers and practitioners. Given the experience we have with ICT and the delivery of career interventions, and the more recent impact of social media in general, it seems appropriate 
to reexamine the role of practitioners in helping persons make effective use of ICT in career interventions. With changes in technology, what are the current potential benefits and limitations of ICT use in career interventions? How have these benefits and limitations shaped the role of practitioners? This paper begins with an examination of the potential benefits and limitations of ICT use and continues with the role of practitioners in promoting effective use of ICT, implications for theory, research, training, and policy, and a conclusion.

\section{Potential Benefits in Using ICT in Career Interventions}

While it is not possible to guarantee the positive outcomes of any innovation, enough experience has accumulated with ICT in career interventions to clearly identify the potential benefits. These potential benefits include improved access to career resources and services, as well as lower costs and greater cost-effectiveness.

\section{Increased Access}

One of the most consistent and tangible benefits resulting from the use of ICT in career interventions is the improvement in access. Persons no longer need to travel to a career center or public library to access career assessments or information as these are readily available on personal computers or mobile devices. Similarly, persons no longer need to travel to a career center to talk with a practitioner who is now available from a distance via ICT-based intervention including social media. Two factors that drive increased access are necessity and convenience (Sampson \& Bloom, 2001). For an individual with a disability, physical and travel barriers are overcome by accessing career resources and services at home. Similarly, for an individual living in a remote geographic area, travel barriers are overcome by obtaining resources and services wherever Internet access is available. In these situations, necessity is the driving factor. For other persons, the ability to access assessments and information at any time, any place and on any device, or access practitioners and their peers early in the morning or late at night, provides expanded opportunities to receive assistance with career problems. In these situations, convenience is the driving factor.

Increased access to assessment. Access to assessments increased substantially with the advent of the Internet where automatic scoring and personalized immediate feedback can be provided. The increase in number of assessments available resulted from the creation of computer versions of existing paper-and-pencil tests and the creation of new assessments available only on the Internet. Assessments incorporated as part of computer-assisted career guidance systems available on the Internet has further increased access (Sampson et al., 2013).

Increased access to information. Similar to assessment, the Internet substantially increased access to career information (Gore \& Leuwerke, 2008; Hooley et al., 2010). Locating information resources to meet specific needs has become more efficient as a result of increasingly powerful search engines (Sampson, 1998; Hooley et al., 2010). As the data transfer (streaming) capacity of the Internet has grown, the access to video-based and media-rich career information has grown as well. The availability of this media-rich information has increased the opportunities for learning about occupational, educational, training, and employment options (Sampson \& Bloom, 2001). The inclusion of career information in computer-assisted online career guidance systems has further increased access to information. Access to career information has been expanded with the creation of social media-based career information. Social media-based career information is occupational, educational, training, and employment information developed and disseminated by users of the information (Sampson et al., 2018). In reflecting and sharing what they are learning, individuals are using social media to become producers of information (Kettunen, Sampson, \& Vuorinen, 2015a). The Internet now includes substantial collaboratively constructed content derived from users in addition to experts (Epstein \& Lenz, 2008; Hooley, 2012; Kettunen \& Makela, 2018; Kettunen, Vuorinen, \& Sampson, 2015b; Makela, 2015; Sampson \& Osborn, 2015). This information is disseminated via discussion threads, Wikis, blogs, social networking sites, and video sharing sites (Sampson et al., 2018).

Increased access to practitioners at a distance. The increasing data transfer capabilities of the Internet has made delivering career interventions at a distance a practical reality. To date, most of the career intervention literature has focused on distance counseling. Distance interventions can be delivered via e-mail, chat, telephone, or videoconferencing and ranges from practitioners answering simple questions to the provision of counseling (Flederman \& Watts, 2014; Richards \& Vigano, 2013; Sampson, 2008). Richards and Vigano (2013) noted that evidence of beneficial outcomes of distance counseling is preliminary, but positive. Distinctive factors that contribute to positive outcomes include (a) anonymity (Gati \& Asulin-Peretz, 2011; Richards \& Vigano, 2013; Sampson et al., 2013), (b) a loss of verbal and visual cues in chat and e-mail that leads to a perception of safety and 
disinhibition among some clients (Richards \& Vigano, 2013), (c) convenience (Richards \& Vigano, 2013), (d) the opportunity to thoughtfully reflect on practitioner and client texts and e-mails before responding (Richards \& Vigano, 2013) and after the sessions, and (e) client access to distance practitioners with specialized competencies (Sampson \& Bloom, 2001). Richards and Vigano (2013) observed that achieving these benefits requires that the client and practitioner have good skills in reading, writing, and computer literacy. Practitioners also need appropriate training for delivering career interventions at a distance (e.g. Bimrose, Kettunen, \& Goddard, 2015). The distinctive factors above, coupled with unanticipated high demand from clients (Richards \& Vigano, 2013), have increased access to career interventions. Ostrowski and Collins (2016) noted that this increase in access is especially the case for clients who do not seek traditional forms of counseling. Flederman and Watts (2014) observed that increased access to practitioners via mobile devices is especially important in developing countries where mobile phones are more common than computers.

Increased access to peer and practitioner support via social media. In addition to practitioners, clients and individuals have long discussed their career choices with significant others, typically friends and family members (Sampson, Peterson, Reardon, \& Lenz, 2000), as well as with personal acquaintances and individuals where no personal relationship exists. Social media provides convenient asynchronous and synchronous exchange of text, visuals and video among friends and family, as well as practitioners and other individuals in the process of making educational and career choices. Social media has increased individuals' access to career interventions. It has become an increasingly important tool for extending career services (Hooley et al., 2010; Kettunen, 2017; Kettunen, Vuorinen, \& Sampson, 2013; Osborn, Dikel, \& Sampson, 2011, Sampson et al., 2018). Hooley (2011) described social media as "a range of internet technologies which enable people to publish their own web content and to connect with other people" (p. 4). Hooley also observed that, social media is effective in sourcing and aggregating the opinions of many people. Social media can create a sense of community and facilitate the support from peers and significant others. Kettunen et al. (2015a) noted that social media allows individuals and groups to reflect and develop common understandings and meanings in career related issues. It can encourage people to seek help (Robinson, Rodrigues, Fisher, Bailey, \& Herrman, 2015) and share information and resources (Lerman et al., 2017). Social media expands the scope of career interventions from individual and group approaches to self-help and selfmanagement approaches (Kettunen et al., 2013). Social media has created a shift in guidance locus from being supplier-driven bound by time and space to a user-driven experience that is ubiquitous (Kettunen et al., 2013). Barnes, La Gro, and Watts (2010) described this shift in terms of a progression in career intervention from being led by the provider to being led by the user. Benefits of social media technologies include improved efficiency of career resources and services (Makela, 2015) and improved accessibility and anonymity (Kettunen et al., 2015b).

\section{Lower Costs and Improved Cost-Effectiveness}

As the per unit costs of data processing has decreased over time, the use of ICT in career interventions has reduced the costs of creating and delivering career resources and services (Bimrose, et al., 2015; Clark, Horan, Tompkins-Bjorkman, Kovalski, \& Hackett, 2000; Gati \& Asulin-Peretz, 2011; Hooley et al., 2010), as well as improving cost-effectiveness (Watts, 2010).

\section{Potential Limitations in Using ICT in Career Interventions}

While increased access to career interventions and reduced costs are undeniably beneficial outcomes of using ICT, this innovation is not without drawbacks. Extensive experience with ICT suggests potential limitations in the following areas: assessment quality, information quality, practitioner support for clients and individuals when needed, distance intervention, peer and practitioner support via social media, confidentiality and security of client records, equality of access, practitioner competencies and credentials, and implementation of ICT in organisations.

\section{Assessment Quality}

Concerns related to the quality of online career assessments was an early issue in the use of ICT in counseling (Sampson \& Pyle, 1983) and persists today (Sampson \& Makela, 2014). Although quality assessments do exist, evidence of the reliability and validity of career assessments administered online is inconsistent (Barak, 2003; Gore \& Leuwerke, 2008; Offer \& Sampson, 1999; Osborn et al., 2011; Sampson \& Bloom, 2001; Sampson et al., 2013). Some paper-based assessments have been adapted and validated, but the computer-based version has no evidence of equivalence; while many assessments available only on the Internet have little or no evidence of quality (Osborn et al., 2011; Sampson, \& Makela, 2014). A further problem involves unvalidated interpretations of assessments (Oliver \& Zac, 1999). Even if an assessment has adequate evidence of validity and reliability, the 
automated online interpretation may be invalid (Sampson, Purgar, \& Shy, 2003). One approach to addressing this problem is to help clients and individuals become more proficient in evaluating and using online career resources and services (Kettunen et al., 2015a). Educating clients to be more informed consumers (Hooley, 2012; Offer \& Sampson, 1999) helps them be aware of potential problems. It is essential that practitioners are aware of issues of assessment quality.

\section{Information Quality}

Similar to assessment, quality of information was raised as an early problem with ICT (Sampson \& Pyle, 1983) and remains problematic (Sampson \& Makela, 2014). Limitations in information available online include the validity of the data itself due to poor research or bias (Gore \& Leuwerke, 2008; Kettunen et al., 2015a; Osborn et al., 2011; Sampson \& Bloom, 2001), and limitations in data presentation that make the information difficult to use (Osborn et al., 2011). Even if the information is valid, there is often little evidence provided for the practitioner, the client, or the individual to use in selecting good quality data. The socially constructed and low-cost nature of social media-based career information creates some specific problems, including lower expectations for the information to be vetted as accurate (Hooley et al., 2010) and difficulty in assessing the accuracy of the information due to a lack of information on authorship, currency, and geographic location. Potential sources of information invalidity include: (a) intentional bias, (b) unintentional bias, (c) restricted range of experience, (d) out-of-date information, (e) popularity bias, (f) similarity bias, and (g) context deficiency (Sampson et al., 2018). One way that practitioners can address this problem is by contributing to the design, evaluation and validation of ICT applications (Sampson \& Osborn, 2015: Sampson et al., 2003) and deepen their understanding of the ethical use of social media in career services (Kettunen \& Makela, 2018).

\section{Practitioner Support for Clients and Individuals when Needed}

It has long been recognized that clients and individuals vary in their capacity to make independent use of ICT (Sampson \& Pyle, 1983). Successful use of career interventions is influenced by readiness for decision making (Epstein \& Lenz, 2008; Sampson, McClain, Musch, \& Reardon, 2013; Sampson et al., 2000). "Individuals with lower readiness for career decision making need more assistance in order to make effective use of career resources, while individuals with higher readiness need little or no support from a practitioner to use career resources" (Sampson \& Makela, 2014, p. 139). While individuals with high readiness may be able to select and use assessment, information, and communication resources without help from a practitioner, individuals with low readiness may have thoughts, emotions, and behaviors that make autonomous selection and use of resources difficult (Osborn et al., 2011).

Experience in using ICT in career interventions has shown that some clients and individuals need practitioner intervention to benefit from using assessments and information. Savard, Gringras, and Turcotte (2002) observed that some clients find it difficult to locate and use relevant information in career decision making. Some individuals using a computer-assisted psychoeducational program reported needing more help in understanding how to use the application (Krumboltz \& Winzelberg, 1997). Gati and Asulin-Peretz (2011) and Vuorinen, Sampson, and Kettunen (2011) observed that some individuals may not choose an ICT application that is best suited to their needs. It is also possible that some individuals with low readiness for decision making may be particularly overwhelmed with information from search engines (Sampson \& Makela, 2014). Herman (2010) found that including practitioner intervention with ICT resulted in positive career development gains. Ball (1990) found that computer-assisted career guidance system use resulted in greater gains when practitioners recommended system features to specific individual needs, when progress was monitored, and when feedback was provided after system use. Niles and Harris-Bowlsbey (2013) concluded that the best intervention for some clients combines ICT use with counseling, which could be either face to face or at a distance.

Osborn, Kronholz, Finklea, and Cantonis (2014) noted that practitioners' evaluation of the level of support clients need to make effective use of ICT is an important aspect of a career intervention. Sampson and Osborn (2015) observed that the primary role of the practitioner in relation to ICT-based career interventions is to assist clients and individuals in selecting, accessing, and using good quality ICT applications that are appropriate for their needs. Gore, Bobek, Robbins, and Shayne (2006) observed that counseling intervention models for ICT-based interventions share similar steps, which typically include preparing individuals, monitoring use, and processing results. Counseling intervention models have been developed by Barnes et al., (2010), Bimrose et al. (2015), and Osborn et al. (2011). Specific competencies for using ICT in career interventions have been proposed by Cogoi 
(2005), Pyle (2001), and Silverii and Busi (2009). Specific competencies for using social media have been proposed by Kettunen (2017).

\section{Distance Intervention}

While practitioners have less experience with distance intervention compared to ICT-based assessment and information resources, some potential limitations have become apparent. In their review of online counseling, Richards and Vigano (2013) noted that many practitioners did not have clients provide informed consent and did not show evidence of compliance with established professional standards for online counseling. Richards and Vigano (2013) also noted that distance counseling requires both clients and practitioners to have adequate written expression skills and computer skills. At this initial stage of development, it is uncertain how well practitioners are ensuring that clients have the skills necessary to succeed with this type of intervention. A final issue involves the potential that the practitioner has a limited awareness of local conditions, events, and cultural issues that may be impacting clients (Osborn et al., 2011; Sampson \& Makela, 2014). The models for face-to-face practitioner support of clients using ICT-based career interventions mentioned previously also apply in a distance intervention mode. Bimrose et al. (2015) emphasized the need for adequate supervision for online practice.

\section{Peer and Practitioner Support via Social Media}

While less is known about the provision of peer and practitioner support to clients and individuals via social media in comparison with other uses of ICT in career intervention, some limitations are clear. Makela (2015) noted potential problems in digital exclusion and confidentiality, security, and privacy of information. Finally, in the provision of information, peers and acquaintances are susceptible to the potential sources of information invalidity noted above by Sampson et al. (2018). Privacy and confidentiality issues were also identified by Kettunen et al. (2015a). It is not clear that an adequate critical mass of practitioners possesses the competencies noted by Kettunen et al. (2015a) required to be effective in social media helping interactions. Consistently following a specific conceptual model, such as the support strategies for social media proposed by Bimrose et al. (2015) and deepening the understanding of the ethical use of social media (Kettunen \& Makela, 2018) should lessen the potential problems identified above.

\section{Confidentiality and Security of Client Records}

Confidentiality and security issues were identified early on as a potential problem in the use of ICT in counseling (Sampson \& Pyle, 1983). The improved access noted previously as benefits in using ICT in career interventions, creates problems with regard to the confidentiality and security of client case notes and assessment data (Kettunen et al., 2015b; Osborn et al., 2011; Sampson, \& Makela, 2014). With regard to distance counseling, Richards and Vigano (2013) noted the problem of practitioners' inconsistent use of data encryption to ensure security of client data in distance counseling. Kettunen et al., (2015a) emphasized the need to educate clients and individuals about privacy issues with social media.

\section{Equality of Access}

Equality of access has also long been a concern in the use of ICT (Haring-Hidore, 1984). Consistent concerns have been raised about equality of access to ICT where limited financial resources should not be a barrier to access (Osborn et al., 2011; Sampson, 1998; Sampson \& Bloom, 2001). A related factor that reduces equality of access is the digital divide, which refers to Internet haves and have nots (Bimrose, Hughes \& Barnes, 2011; Hooley, 2012). This concept goes beyond not having the financial resources for ICT access to not having the digital literacy to know how to access and use information resources (Bimrose et al., 2011; Hooley et al., 2010). Sampson, Dozier, and Colvin (2011) observed that reduced access to counseling resources and services is a social justice issue. While the digital divide is less of a problem today than it has been in the past, it has not disappeared (Kettunen \& Sampson, 2018) and still requires attention.

\section{Practitioner Competencies and Credentials}

Since the initial adoption of ICT in counseling and guidance, the need for training to ensure adequate practitioner competencies has been recognized (Sampson \& Pyle, 1983). Kettunen and Sampson (2018) found inadequate practitioner competencies to be a problem in the delivery of ICT-based career interventions. In terms of distance counseling, Richards and Vigano (2013) observed considerable variation in the credentials of practitioners providing online counseling. It was further observed that practitioner credentials for online services are often vague or not stated (Osborn et al., 2011; Richards \& Vigano, 2013). 


\section{Implementation of ICT in Organisations}

As was the case with most other limitations in ICT-based career interventions, implementation has been a concern since the beginning (Sampson, 1984) and is still a problem in service delivery (Sampson \& Bloom, 2001). "Problems that commonly undermine effective implementation included poor planning, a lack of practitioner participation in decision making, poor integration of new technologies within service delivery organisations, inadequate staff training, poor evaluation, and staff anxiety and resistance” (Kettunen \& Sampson, 2018, p. 2). Bimrose et al. (2015) observed that the integration of ICT into careers practice is neither uniform or coherent. Guiding the implementation of ICT in organisations has long been viewed as an important role of the practitioner (Sampson \& Pyle, 1983; Walz, 1984). An important aspect of the implementation process involves ensuring that the delivery of resources and services is congruent with current ethical, credentialing, and accreditation standards (Makela, 2015; Sampson \& Makela, 2014). Sampson (2008) described an eight-step implementation model that practitioners can use for ICT-based career interventions. This model incorporates both ICT and non-ICT-based career interventions, increasing the likelihood that all resources and services are well managed, evidence-based practice is established, and continuous improvement is in effect.

\section{Practitioner Role in Promoting Effective Use of ICT-Based Career Interventions}

The above literature describing the benefits and limitations in using ICT-based career interventions suggest specific roles for practitioners in making effective and responsible use of these applications. Key aspects of these roles are summarized in Table 1.

Table 1

Key Aspects of the Role of the Practitioner in ICT-Based Career Interventions

Assessment and Information Quality

Practitioners recommend only valid assessments and information resources to clients and individuals that meet standards and relate to specific needs.

Practitioner Support for Clients and Individuals when Needed

Practitioners need to have a valid basis for determining which clients and individuals are likely to need support to benefit from an ICT-based career intervention.

Practitioners use an explicit intervention model for providing a type and amount of assistance that is appropriate for clients' characteristics and needs.

Distance Intervention

Practitioners need to make clients aware of the benefits and limitations of distance intervention and the factors that contribute to successful outcomes.

Practitioners need to ensure that they and their clients have adequate skills to work at a distance.

Practitioners have adequate supervision from a professional experienced in distance interventions.

Peer and Practitioner Support via Social Media

Practitioners need to make clients and individuals aware of privacy issues with social media and how to use social media tools to manage their privacy.

Practitioners need to make recommendations on how to identify and use information that fits individuals' needs and circumstances.

Practitioners need to monitor and challenge posts and links on social media sites maintained by the organisation where they are employed that present inaccurate, stereotypical, or dangerous information.

Confidentiality and Security of Client Records

Practitioners need to maintain the confidentiality and security of client records and ensure that clients and individuals are aware of these protections and provide informed consent.

Equality of Access

Practitioners provide information to clients and individuals who may have limited finances or digital literacy as to where they can obtain support to access the Internet.

Practitioner Competencies and Credentials

Practitioners need to fully describe their competencies and credentials on the Internet.

Practitioners should limit referrals to only practitioners who fully describe competencies and credentials that specifically relate to client or individual needs. 


\section{Implementation of ICT in Organisations}

Practitioners actively participate in the implementation of ICT-based career interventions to avoid preventable problems and maximize intervention effectiveness.

Practitioners actively participate in the periodic evaluation of ICT-based career interventions, as well as contributing future design recommendations where possible.

Practitioners periodically contribute to public policy on the design and use of ICT-based career interventions. Professional Standards

Practitioners need to be aware of and follow appropriate professional standards for ICT use in assessment, information, practitioner support for clients and individuals when needed, distance interventions, confidentiality and security of client records, ensuring equality of access, and ensuring adequacy of practitioner competencies and credentials.

Practitioners periodically work to educate clients and individuals to recognize quality ICT-based career interventions.

\section{Evolution in the Role of the Practitioner in Organizations as a Result of Social Media}

ICT has been influencing the evolution of career interventions for some time. Thirty-four years ago, Garry Walz, an early innovator in ICT and counseling observed, "In light of the enormous potential of the computer, we must look to the creative redesign of counseling" (Walz, 1984, p. 137). The integration of social media into career services is prompting a redesign of service delivery, particularly in reconsideration of the role of the practitioner. Practitioners using social media in career interventions have a variety of perceptions regarding the role of the practitioner, ranging from using social media to provide expert information, to using social media in a reflexive oneto-one dialogue, to using social media to facilitate interaction among groups of individuals, to using social media in actively participating and engaging communities of individuals around career issues (Kettunen et al., 2015a). This last function can be described as co-careering, which involves "the shared expertise and meaningful co-construction of career issues among community members” using social media (Kettunen, 2017, p. 41).

Success in this expanded aspect of practitioner role requires the practitioner to be an active participant in social media by acquiring the requisite skills, establishing a visible, approachable, and trusted social media presence, and using this social media presence in the delivery of career interventions (Kettunen et al., 2015a; Sampson et al., 2018). Larbalestier (2010) added that practitioners also have an important role in monitoring individuals' use of social media. The question arises, however, how can this be best accomplished when practitioners are already busy with numerous tasks?

The following strategies are recommended to operationalize a visible and trusted online presence. First, practitioners need to establish foundational skills in successful participation in social media (Kettunen \& Makela, 2018; Hooley, 2011). Contributing to the design and implementation of the social media strategy, as well as ensuring that common guidelines and/or social networking policies are in place for their organisation would be important steps (Kettunen \& Makela, 2018; Hooley, 2011). Second, practitioners need to establish their own social media presence utilizing current social media tools (Kettunen et al., 2015a). Third, practitioners need to monitor social media posts within their organisations' social media in order to (a) reactively respond to requests for information or services, (b) proactively recommend resources and services that fit individual characteristics and needs, and follow-up as appropriate, (c) proactively take advantage of opportunities for co-careering among the community members that their organisation serves, identifying teachable moments and responding to these, and (d) participate in social media sites maintained by the organisation where they are employed by answering questions or requests, recommending resources and services as appropriate, marketing their organisation and other sources of assistance, and engaging in co-careering as opportunities emerge. It is important for practitioners to monitor clients' and individuals' statements which may include possible harm to themselves or others, statements indicating potential abuse of vulnerable persons, and statements indicating stereotypes or discrimination that limit persons' opportunities. The terms of use for the social media site of an organisation needs to include notification that practitioners from the organisation may monitor and respond to social media posts. Mowery et al. (2017) demonstrated an approach to monitoring social media posts using human coding and machine learning. Fourth, practitioners need to use data analytics to understand the reach, impact, and utilization of their social media presence. Fifth, practitioners need to engage in evaluation and continuous improvement strategies to enhance the social media strategy of the organisation. Sixth, practitioners should receive supervision to improve their social media practice. 
One important barrier to implementing the above recommendations is managing the substantial volume of social media posts related to a particular organisation. How do practitioners prioritize which social media posts deserve prompt attention and which posts can be responded to later, or not at all? In large organisations, practitioners do not have enough time to read all of the posts, let alone respond. This is especially true when practitioners have responsibilities for multiple services. One potential solution lies in the technological capacity of social media sites and the expertise we have in career interventions. Social media sites already have the capacity to monitor posts. What they lack are algorithms based on theory, empirical data, and expert professional judgment that can prioritize posts for practitioner attention. A popular crisis text line (https://www.crisistextline.org/) already prioritizes texts for practitioner response on the basis of individuals' danger to themselves or others. The algorithm that prioritizes texts for practitioner response is based on readily available empirical data on crisis. By using existing theory on readiness for decision making and mental health, empirical data on the characteristics of individuals who are most at risk of career disengagement or harm from self or others, and expert professional judgment on setting priorities for care, social media sites can help practitioners prioritize their time to serve clients and individuals with the greatest need. This type of social media content monitoring using a simple type of artificial intelligence can assist practitioners in creating a social media presence that is achievable given typical resource constraints.

\section{Implications}

Given that distance interventions and practitioner interventions with social media have received less attention in the literature on career interventions, the implications section will focus on these areas.

\section{Implications for Theory and Research}

Richards and Vigano (2013) identified a need for theory development and research in distance counseling. Examples of theoretical and research questions include the following. What are the curative and working alliance factors in distance counseling and how are these factors similar and different from face-to-face counseling? How do synchronous and asynchronous distance intervention modalities interact with individual characteristics and problems? How does readiness for career decision making influence outcomes in distance interventions? Similar efforts in theory and research are needed regarding co-careering. For example, Kettunen (2017) emphasized a need for further research to establish evidence on how the processes of co-careering are similar and different from more traditional independent career decision making? What client and practitioner characteristics contribute to success in co-careering? How does readiness for career decision making influence outcomes in co-careering?

\section{Implications for Training}

The need for training associated with distance and social media-based career interventions is well established (Bimrose et al., 2011; Kettunen et al., 2013; Richards \& Vigano, 2013; Vuorinen et al., 2011). Kettunen et al. (2015b) stressed the need for both preservice and in-service training. Adequate training should help practitioners to feel confident and competent in their work which facilitates successful integration of ICT into practice. Specific practitioner training competencies related to social media include the proficiency to locate, evaluate, and use online content, being a versatile and thoughtful writer, the capacity to generate and maintain engaging and constructive online discussions, and creating a visible and trusted online presence (Kettunen, 2017; Kettunen et al., 2015a). Kettunen, et al. (2015b) also emphasized training in interventions that foster collaborative processes in career learning among peer group members.

\section{Implications for Policy}

Early intervention related to making occupational, educational, training, and employment choices has been a policy goal for many years. In many countries career development has been planned and organized within different government sectors. The use of technology requires a new culture based on co-ordination and co-operation in order to make efficient use of scare resources. The use of emerging technologies make access to career services more feasible through more diverse service delivery. Given the general popularity of social media and distance communication among young people, co-operation and co-ordination between government sectors is particularly important from a citizen perspective where individualized solutions require a coordinated response from variety of agencies. Technology has the potential to act as an integrative factor in career development policy if ministries and agencies that share responsibility for career services have a commonly agreed on framework for the role and use of technology and communicate this to service providers and stakeholders. This approach requires that the use of ICT in career services needs to be treated as part of national e-Governance policies and there is an appropriate 
infrastructure for the development and implementation of the services, especially training and support for the service providers (ELGPN, 2015).

In meeting the needs of those who are less familiar with this technology, the policies need to recognize the differences in digital literacy and integrate the use of ICT in ongoing career education where individuals can develop skills on how to use online services and how to be present in social media. Digital inclusion can also be promoted by allocating resources for public access with accompanying support for those who need it.

ICT facilitates communication and collaborative construction of knowledge from users and providers and generates a large amount of evidence for practice and policy development. The use of ICT in career services should be integrated into national quality assurance mechanisms and vice versa. The existing open data on the use of the services could be elaborated as an evidence base for career development policies. This requires that research and development funding should be allocated for social media content monitoring even in times when multiple priorities exist.

\section{Conclusion}

With respect to the questions posed at the beginning of this paper, although technology has changed dramatically over fifty years, the benefits and limitations associated with ICT use in career interventions have remained relatively consistent. The benefits of increased access to career interventions continues to expand as technology develops; early ethical and professional issues remain limitations that practitioners continue to have a role in addressing. The role of practitioners remains crucial in taking advantage of the benefits and ameliorating the limitations. However, the emergence of social media in the delivery of career interventions has accelerated an evolution in the practitioner role that is additive rather than subtractive. While the original expert role of the practitioner remains relevant, the expertise has evolved from the delivery of expert knowledge to expertise in designing and managing guidance processes. Interaction with clients and individuals is becoming more collaborative. As technology continues to evolve, the role of the practitioner will need to evolve as well; hopefully keeping the best of the past while taking advantage of new opportunities.

As noted by Walz (1970), awareness of the potential positive and negative impact of ICT has existed since the initial use of this technology. In this paper, many of the same elements have created both benefits and limitations that occur simultaneously. Despite this combination of potential positive and negative outcomes, ICT provides an opportunity to do familiar things differently or do things that were not possible before, as Walz noted in 1970 . We now have the opportunity to integrate best practices of past ICT use in career interventions with the use of distance interventions and social media to do familiar tasks in new ways, as well as provide new types of support for clients and individuals that would have been difficult to imagine in the past.

\section{References}

Ball, B. (1990). Integrating PROSPECT into an HE careers programme. In A. G. Watts, V. Butcher, \& C. Cooper (Eds.), Guidance and educational change: A cross-sectoral review of policy and practice (p. 31). Cambridge, UK: Careers Research and Advisory Centre.

Barak, A. (2003). Ethical and professional issues in career assessment on the Internet. Journal of Career Assessment, 11, 3-21. doi:10.1177/106907202237457.

Barnes, A., La Gro, N., \& Watts, A. G. (2010). Developing e-guidance competencies: The outcomes of a two-year European project to transform the professional development of career guidance practitioners. Career Research and Development: The NICEC Journal, 25, 26-32.

Bimrose, J., Hughes, D., \& Barnes, S.-A. (2011). Integrating new technologies into careers practice: Extending the knowledge base. London: UK Commission for Employment and Skills.

Bimrose, J., Kettunen, J., \& Goddard, T. (2015). ICT - the new frontier? Pushing the boundaries of careers practice. British Journal of Guidance \& Counselling, 43, 8-23, doi:10.1080/03069885.2014.975677

Clark, G., Horan, J. J., Tompkins-Bjorkman, A., Kovalski, T., \& Hackett, G. (2000). Interactive career counseling on the Internet. Journal of Career Assessment, 8, 85-93. doi:10.1177/106907270000800107

Cogoi, C. (Ed.) (2005). Using ICT in guidance: Practitioner competencies and training. Report of an EC Leonardo project on ICT skills for guidance counselors. Bologna, Italy: Outline Edizione. 
ELGPN [European Lifelong Guidance Policy Network]. (2015). The guidelines for policies and systems development for lifelong guidance: A reference framework for the EU and for the commission. ELGPN Tools No. 6. Saarijärvi, Finland.

Epstein, S., \& Lenz, J. G. (2008). Developing and managing career resources. [Monograph]. Broken Arrow, OK: National Career Development Association.

Flederman, P., \& Watts, A.G. (2014). Career helplines: A resource for career development. In G. Arulmani, A. J. Bakshi, F. T. L. Leong, \& A. G. Watts (Eds.), International and cultural psychology. Handbook of career development: International perspectives (pp. 481-493). New York, NY, US: Springer Science + Business Media. doi:10.1007/978-1-4614-9460-7_27

Gati, I., \& Asulin-Peretz, L. (2011). Internet-based self-help career assessments and interventions: Challenges and implications for evidence-based career counseling. Journal of Career Assessment, 19, 259-273. doi:10.1177/1069072710395533

Gore, P. A., Jr., Bobek, B. L., Robbins, S. B. \& Shayne, L. (2006). Computer-based career exploration: Usage patterns and a typology of users. Journal of Career Assessment, 14, 421-436. doi:10.1177/1069072706288939

Gore, P. A., Jr., \& Leuwerke, W. C. (2008). Computer-assisted career counseling. Encyclopedia of counseling (pp. 1510-1514). Thousand Oaks CA: Sage.

Haring-Hidore, M. (1984). In pursuit of students who do not use computers for career guidance. Journal of Counseling and Development, 63, 139-140. doi:10.1002/j.1556-6676.1984.tb02784.x

Herman, S. (2010). Career HOPES: An Internet-delivered career development intervention. Computers in Human Behavior, 26, 339-344. doi:10.1016/j.chb.2009.11.003

Hooley, T. (2011). Gathering career wisdom from Facebook and other social media. Connect, 5: 4-5.

Hooley, T. (2012). How the internet changed career: Framing the relationship between career development and online technologies. Journal of the National Institute for Career Education and Counselling, 29, 2-12.

Hooley, T., Hutchinson, J., \& Watts, A. G. (2010). Careering through the web: The potential of Web 2.0 and 3.0 technologies for career development and career support services. London: UK Commission for Employment and Skills.

Kettunen, J. (2017). Career practitioners' conceptions of social media and competency for social media in career services. Jyväskylä, Finland: University of Jyväskylä, Finnish Institute for Educational Research. Studies, 32.

Kettunen, J. \& Makela, J. (2018). Practitioners' conceptions of ethical practice in social networking in career services. International Journal for Educational and Vocational Guidance. Advance online publication. doi:10.1007/s10775-018-9383-4

Kettunen, J., \& Sampson, J. P. (2018). Challenges in implementing ICT in career services: Perspectives from career development experts. International Journal of Educational and Vocational Guidance. Advance online publication. doi:10.1007/s10775-018-9365-6

Kettunen, J., Sampson, J. P., \& Vuorinen, R. (2015a). Career practitioners' conceptions of competency for social media in career services. British Journal of Guidance \& Counseling, 43, 43-56. doi:10.1080/03069885.2014.939945

Kettunen, J., Vuorinen, R., \& Sampson, J. P. (2015b). How do career practitioners experience social media in career services? The Career Development Quarterly, 63, 268-282. doi:10.1002/cdq.12018

Kettunen, J., Vuorinen, R., \& Sampson, J. P. (2013). Career practitioners' conceptions of social media in career services. British Journal of Guidance \& Counseling, 41, 302-317. doi:10.1080/03069885.2013.781572

Krumboltz, J. D., \& Winzelberg, A. (1997). Technology applied to learning and group support for career related concerns. Career Planning and Adult Development Journal, 13, 101-110.

Larbalestier, M. (2010). The social web and careers work. Career Research \& Development: the NICEC journal, 25, 4-6.

Lerman, B. I., Lewis, S. P., Lumley, M., Grogan, G. J., Hudson, C. C., \& Johnson, E. (2017). Teen depression groups on Facebook: A content analysis. Journal of Adolescent Research, 32, 719-741. doi:10.1177/0743558416673717

Makela, J. (2015). Ethical use of social networking technologies in career services. Broken Arrow, OK: National Career Development Association. Retrieved from https://www.ncda.org/aws/NCDA/asset_manager/get_file/110167

Mowery, D., Smith, H., Cheney, T., Stoddard, G., Coppersmith, G., Bryan, C., \& Conway, M. (2017). Understanding depressive symptoms and psychological stressors on Twitter: A corpus-based study. Journal of Medical Internet Research, 19(2), e48. doi:10.2196/jmir.6895. 
Niles, S. G., \& Harris-Bowlsbey, J. (2013). Career development interventions in the 21st Century (4th ed.). Boston, MA: Pearson.

Offer, M., \& Sampson, J. P. (1999). Quality in the content and use of information and communications technology in guidance. British Journal of Guidance and Counselling, 27, 501-516. doi:10.1080/03069889908256286

Oliver, L. W., \& Zack, J. S. (1999). Career assessment on the Internet: An exploratory study. Journal of Career Assessment, 7, 323-356. doi:10.1177/106907279900700402.

Osborn, D. S., Dikel, M. R., \& Sampson, J. P. (2011). The Internet: A tool for career planning (3rd ed.). Broken Arrow, OK: National Career Development Association.

Osborn, D., Kronholz, J. F., Finklea, J. T., \& Cantonis, A. M. (2014). Technology-savvy career counselling. Canadian Psychology, 55, 258-265. doi:10.1037/a0038160

Ostrowski, J., \& Collins, T. P. (2016). A comparison of telemental health terminology used across mental health state licensure boards. The Professional Counselor, 6, 387-396.

Pyle, K. R. (2001). Career counseling in an information age. Career Planning and Adult Development Journal, 16(3), 7-29.

Richards, D., \& Vigano, N. (2013). Online counseling: A narrative and critical review of the literature. Journal of clinical Psychology, 69, 994-1011. doi:10.1002/jclp.21974

Robinson, J., Rodrigues, M., Fisher, S., Bailey, E., \& Herrman, H. (2015). Social media and suicide prevention: Findings from a stakeholder survey. Shanghai Archives of Psychiatry, 27(1), 27-35. doi:10.11919/j.issn.1002-0829.214133

Sampson, J. P. (1984). Maximizing the effectiveness of computer applications in counseling and human development: The role of research and implementation strategies. Journal of Counseling and Development, 63, 187-191. doi:10.1002/j.1556-6676.1984.tb02797.x

Sampson, J. P. (1998). The Internet as a potential force for social change. In C. C. Lee, \& G. R. Walz (Eds.), Social action: A mandate for counselors (pp. 213-225). Greensboro, NC: University of North Carolina, ERIC Clearinghouse on Counseling and Student Services.

Sampson, J. P. (2008). Designing and implementing career programs: A handbook for effective practice. Broken Arrow, OK: National Career Development Association. Retrieved from http://store.ncda.org/ebooks/designing-and-implementing-career-programs-a-handbook-for-effectivepractice-monograph.html

Sampson, J. P., \& Bloom, J. W. (2001). The potential for success and failure of computer applications in counseling and guidance. In D. C. Locke, J. Myers, \& E. L. Herr (Eds.), The handbook of counseling (pp. 613-627). Thousand Oaks, CA: Sage Publications.

Sampson, J. P., Dozier, V. C., \& Colvin, G. P. (2011). Translating career theory to practice: The risk of unintentional social injustice. Journal of Counseling and Development, 89, 326-337. doi:10.1002/j.15566678.2011.tb00097.x

Sampson, J. P., \& Makela, J. P. (2014). Ethical issues associated with information and communication technology in counseling and guidance. International Association for Educational and Vocational Guidance Journal, 14, 135-148. doi:10.1007/s10775-013-9258-7

Sampson, J. P., McClain, M. C., Dozier, C., Carr, D. L., Lumsden, J. A., \& Osborn, D. S. (2013). Computer-assisted career assessment. In C. Wood \& D. G. Hayes (Eds.), A counselor's guide to career assessment instruments (6th ed.) (pp. 33-47). Broken Arrow, OK: National Career Development Association

Sampson, J. P., McClain, M. C., Musch, E., \& Reardon, R. C. (2013). Variables affecting readiness to benefit from career interventions. The Career Development Quarterly, 61, 98-109. doi:10.1002/j.21610045.2013.00040.x

Sampson, J. P., \& Osborn, D. S. (2015). Using information and communication technology in delivering career interventions. In P. J. Hartung, M. L. Savickas, \& W. B. Walsh (Eds.), APA handbook of career intervention, Volume 2: Applications (pp. 57-70). Washington, DC: American Psychological Association. doi:10.1037/14439-005

Sampson, J. P., Osborn, D. S., Kettunen, J., Hou, P. C., Miller, A. K., \& Makela, J. P. (2018). The validity of social media-based career information. The Career Development Quarterly, 66, 121-134. doi:10.1002/cdq.12127

Sampson, J. P., Peterson, G. W., Reardon, R. C., \& Lenz, J. G. (2000). Using readiness assessment to improve career services: A cognitive information processing approach. The Career Development Quarterly, 49, 146-174. doi:10.1002/j.2161-0045.2000.tb00556.x

Sampson, J. P., Purgar, M. P., \& Shy, J. D. (2003). Computer-based test interpretation in career assessment: Ethical and professional issues. Journal of Career Assessment, 11, 22-39. doi:10.1177/106907202237458

Sampson, J. P., \& Pyle, K. R. (1983). Ethical issues involved with the use of computer-assisted counseling, testing 
and guidance systems. Personnel and Guidance Journal, 61, 283-287. doi:10.1111/j.21644918.1983.tb00026.x

Savard, R., Gingras, M. \& Turcotte, M. (2002). Delivery of career development information in the context of information computer technology, International Journal for Educational and Vocational Guidance. 2, 173191. doi:10.1023/A:1020659801270

Silverii, M., \& Busi, B. (Eds.). (2009). ICT Skills 2: ICT tools and training for e-guidance practitioners. Bologna, Italy: ASTER Scienza Tecnologia Impresa S. Cons p.a.

Vuorinen, R., Sampson, J. P., \& Kettunen, J. (2011). The perceived role of technology in career guidance among practitioners who are experienced Internet users. Australian Journal of Career Development, 20, 39-46.

Walz, G. (1970). Technology in guidance: A conceptual overview. Personnel and Guidance Journal, 49, 175-182. doi:10.1002/j.2164-4918.1970.tb03427.x

Walz, G. (1984). Role of the counselor with computers. Journal of Counseling and Development, 63, 135-138. doi:10.1002/j.1556-6676.1984.tb02783.x

Watts, A. G. (2010). Policy issues relating to the use of ICT in lifelong guidance. Career Research Development: The NICEC Journal, 25, 33-39. 